\title{
Endoscopic Ultrasonography-Specific Stents
}

\author{
Rahul Haresh Shah ${ }^{1}$ Priyanka Udawat ${ }^{1}$ Vinay Dhir ${ }^{1}$ \\ ${ }^{1}$ Department of Gastroenterology, Institute of Digestive and Liver \\ Care, S L Raheja Hospital, Mumbai, Maharashtra, India \\ Address for correspondence Rahul Haresh Shah, MRCP (Medicine, \\ Gastroenterology), Department of Gastroenterology, Institute of \\ J Digest Endosc 2021;12:229-234. \\ Digestive and Liver Care, S L Raheja Hospital, Mumbai 400016, \\ Maharashtra, India (e-mail: rahulhshah@hotmail.com).
}

\begin{abstract}
Keywords

- BFMS

- endoscopic ultrasound

- LAMS

The evolution of the endoscopic ultrasonography (EUS) technique has necessitated the development of EUS-specific accessories and stents. In the earlier period, EUS-guided interventions mostly relied on borrowed accessories and stents from therapeutic endoscopy in particular ERCP. Traditional stents do not serve the purpose of EUSguided transluminal stenting in all cases due to the length of the stent, no anchoring mechanism, and chance of migration. From 2011 onward, several EUS-specific stents became available, bringing a paradigm shift in interventional EUS. This article reviews current EUS-specific stents, indications, strengths, and weaknesses.
\end{abstract}

\section{Introduction}

Interventional endoscopic ultrasonography (EUS) has evolved rapidly over the past decade. Many techniques have become standardized and have been integrated into routine patient management in advanced endoscopy units worldwide. Parallel with this development, there has been an accumulation of highquality evidence regarding the safety and efficacy of multiple interventional EUS procedures. There is level 1 evidence for EUS-biliary drainage (EUS-BD) in the distal biliary malignant block, pancreatic fluid collection drainage, and celiac plexus neurolysis. ${ }^{1,2}$ EUS-guided drainage biliary drainage is being used in patients with failed ERCP, ERCP in altered anatomy, or gastric outlet obstruction. ${ }^{3}$ The evolution of the EUS technique has necessitated the development of EUS-specific accessories and stents. ${ }^{4}$ In the earlier period, EUS-guided interventions mostly relied on borrowed accessories and stents from therapeutic endoscopy in particular ERCP. ${ }^{5}$ Traditional stents do not serve the purpose of EUS-guided transluminal stenting in all cases due to the length of the stent, no anchoring mechanism, and chance of migration.

As the experience with interventional EUS increased, the specific requirements from stents became clear. The most important distinction was the need for a covered stent, full or partial, as EUS-guided stents need to traverse across organs such as the stomach, liver, jejunum, duodenum, bile duct, and gallbladder. In the absence of a covered stent, the probability of leaks between organs is high. The extent of the covered portion was different in different regions. For example, hepaticogastrostomy needs long tubular stents with a distal uncovered portion in the intrahepatic ducts to prevent side branch obstruction, and the fully covered portion between the liver capsule and stomach to prevent bile leak. ${ }^{4,5}$

The second issue was the length of the stent. Stents used in ERCP are usually $4 \mathrm{~cm}$ or longer. Such a long stent is not needed for many indications with EUS such as cholecochoduodenostomy, gastro-enterostomy, or pancreatic fluid collection drainage. A short stent length such as 1 to $2 \mathrm{~cm}$ is usually sufficient to bring the two walls together. ${ }^{6} \mathrm{~A}$ longer stent has a propensity to migration, as well as separation of the two anastomosed walls. As described earlier, hepaticogastrostomy needed long tubular stents to traverse from the left lobe of the liver to the proximal stomach.

The third issue was migration. As these stents do not traverse through any stricture or tumor, they can migrate easily. Thus, anti-migration mechanisms in the form of wide flanges or other anchoring mechanisms were needed.
DOI https://doi.org/ 10.1055/s-0041-1741514. ISSN 0976-5042. (c) 2022. Society of Gastrointestinal Endoscopy of India. All rights reserved.

This is an open access article published by Thieme under the terms of the Creative Commons Attribution-NonDerivative-NonCommercial-License, permitting copying and reproduction so long as the original work is given appropriate credit. Contents may not be used for commercial purposes, or adapted, remixed, transformed or built upon. (https://creativecommons.org/ licenses/by-nc-nd/4.0/)

Thieme Medical and Scientific Publishers Pvt. Ltd., A-12, 2nd Floor, Sector 2, Noida-201301 UP, India 


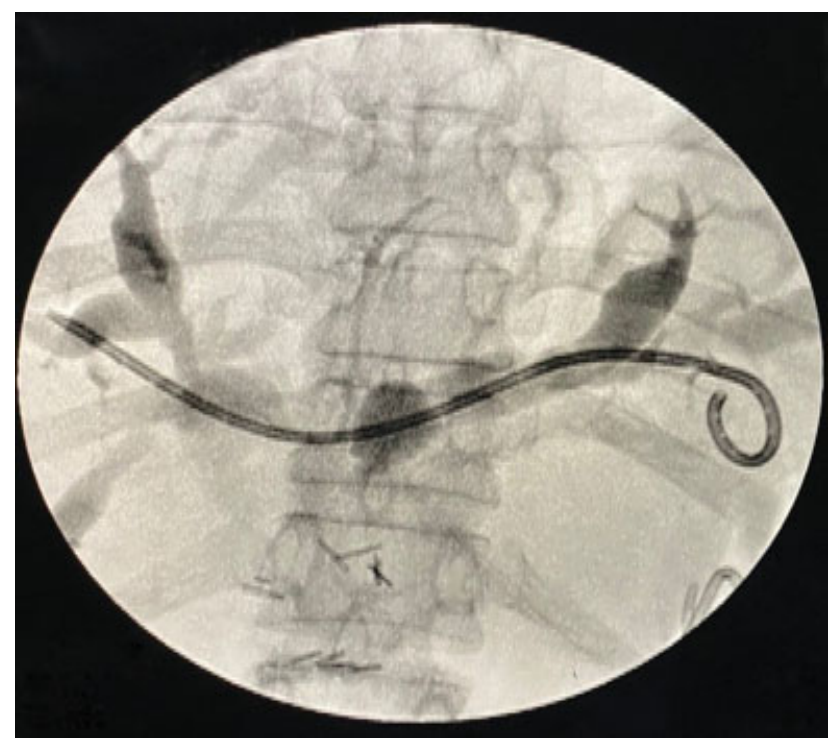

Fig. 1 Cholangiogram showing an IT stent in the left hepatic duct.

Thus around 2011 onward, several EUS-specific stents became available, bringing a paradigm shift in interventional EUS.

\section{Types of Stents}

\section{EUS-Specific Plastic Stents}

Recently, a EUS-specific plastic single pigtail stent (IT stent) was developed by Itoi et al for use in hepaticogastrostomy (HGS) and PD interventions. ${ }^{6}$ The 7 French stent has a tapered tip, four internal flanges (two in the distal end and two at the proximal end), and a single external pigtail (total length of $20 \mathrm{~cm}$ and an effective length of $15 \mathrm{~cm}$ [ - Fig. 1]). The new stent has several advantages namely the tapered and straight distal tip can be easily advanced via the needle tract and stricture sites, and the four flange sand pigtail anchor the stent and prevent outward and inward migration.

\section{EUS-Specific Metal Stents}

There are three types of stent designs available, namely, biflanged fully covered metal stent (BFMS), lumen apposing stents (LAMS), and hybrid tubular stents. We will discuss these stent designs.

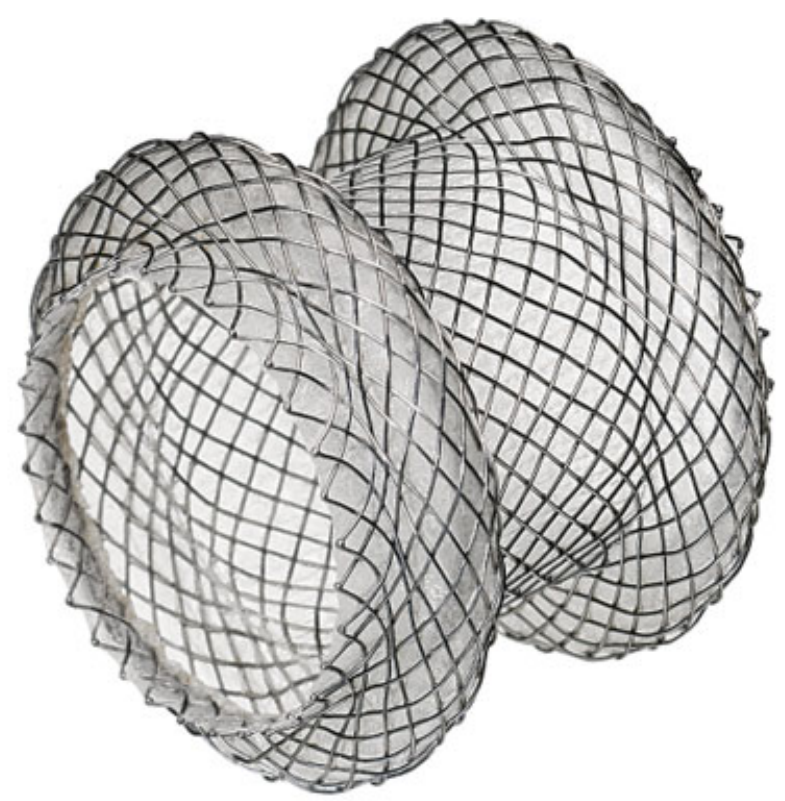

Fig. 2 Axios stent.

\section{Lumen Apposing Stents}

The use of LAMS specifically designed for EUS-guided transluminal drainage was first reported by Binmoeller and Shah in 2011. ${ }^{7}$ They are designed with an inbuilt needle and cautery enhanced features leading to one-step deployment. The stents are fully silicone covered with a self-expanding memory metal such as nickel-titanium alloy, which provides flexibility and adequate radial force to anchor the opposing lumens and prevents migration due to wide flanges on either side. Memory metal helps the stent to expand to desired dimensions and flanges prevent migration by anchoring (-Table 1).

The Hot AXIOS ${ }^{\mathrm{TM}}$ delivery system (Boston Scientific Natick, USA) ( - Fig. 2) has an integrated cautery system that consists of two radially distributed diathermic wires converging around the guidewire lumen, which provides a clean, sharp cut with a minimal coagulation effect. This single-step procedure makes it faster, safer with the need for fewer accessories, thus reducing potential complications. The hot AXIOS does not necessarily need a 19-gauge needle or wire.

The Spaxus stent (Taewoong Medical Co., Ltd., Ilsan, Korea) (-Figs. 3 and $\mathbf{4}$ ) on the other hand has flanges that fold back once fully deployed, which aims to enhance the

Table 1 Comparative data of LAMS stents

\begin{tabular}{|l|l|l|l|l|l|}
\hline Stent type & $\begin{array}{l}\text { Flange } \\
\text { diameter }(\mathbf{m m})\end{array}$ & $\begin{array}{l}\text { Length } \\
(\mathbf{m m})\end{array}$ & $\begin{array}{l}\text { Catheter } \\
\text { diameter (French) }\end{array}$ & $\begin{array}{l}\text { Lumen apposing } \\
\text { force (Newton) }\end{array}$ & Studied applications \\
\hline AXIOS & $6-20$ & 8,10 & 10.8 & 2.29 & GJ, CDS,PFC, GBD \\
\hline SPAXUS & $8-16$ & 20 & 10 & 1.76 & PFC, GBD, G] \\
\hline NAGI & $10-16$ & $10,20,30$ & 9,10 & 1.08 & PFC, GBD \\
\hline AIXSTENT & $10-15$ & 30 & 10 & NA & PFC \\
\hline PLUMBER & $12-16$ & $10,20,30$ & 10.2 & NA & PFC \\
\hline
\end{tabular}

Abbreviations: G], gastrojejunostomy; CDS, cholecochoduodenostomy; PFC, pancreatic fluid collection; GBD, gall bladder drainage. 


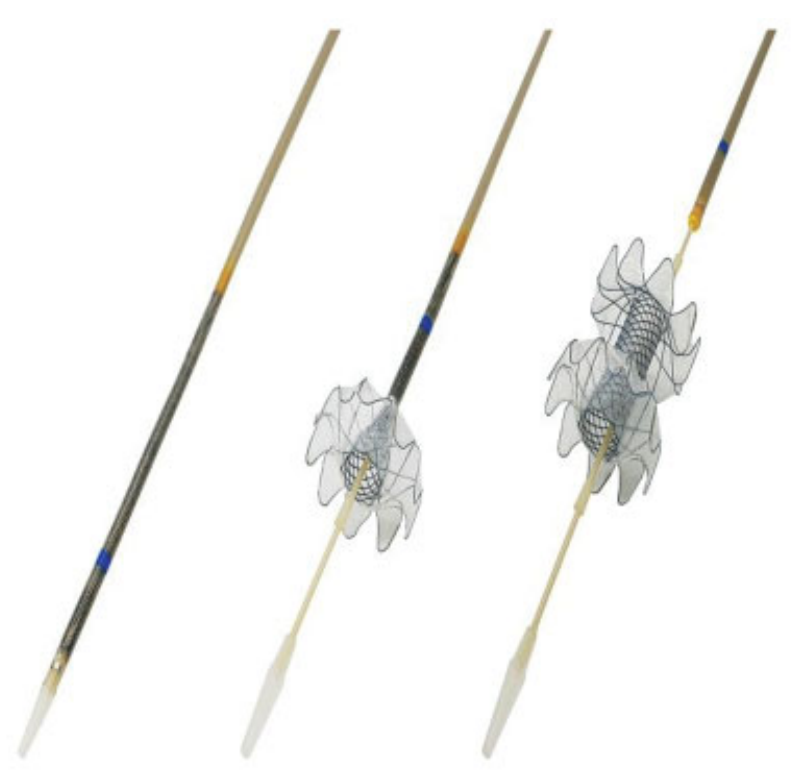

Fig. 3 Spaxus stent.

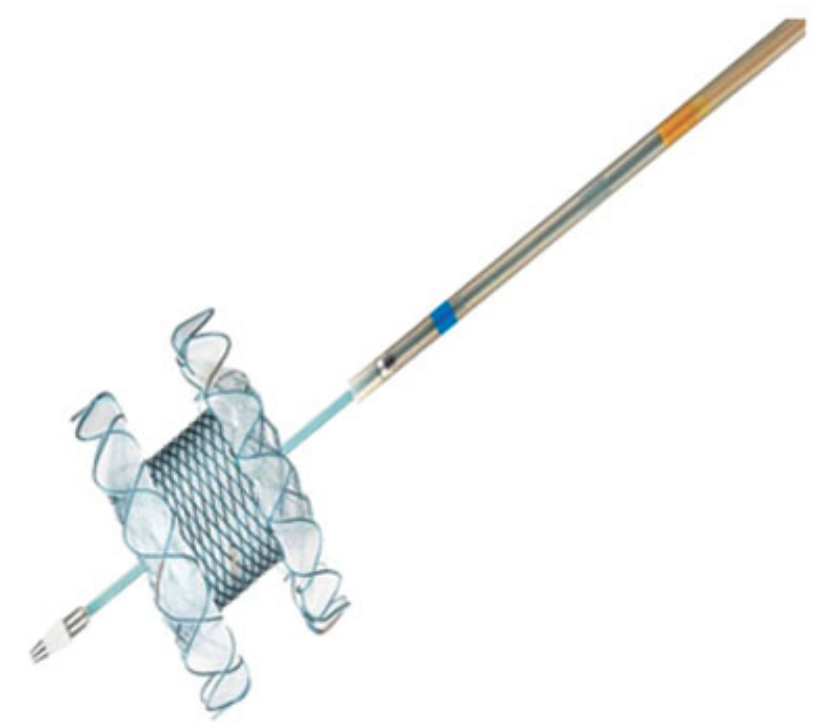

Fig. 4 Hot Spaxus stent.

lumen apposition and prevent migration. Blue marker at the distal flange aids endoscopic accurate placement. It comes in 2 and $3 \mathrm{~cm}$ lengths.

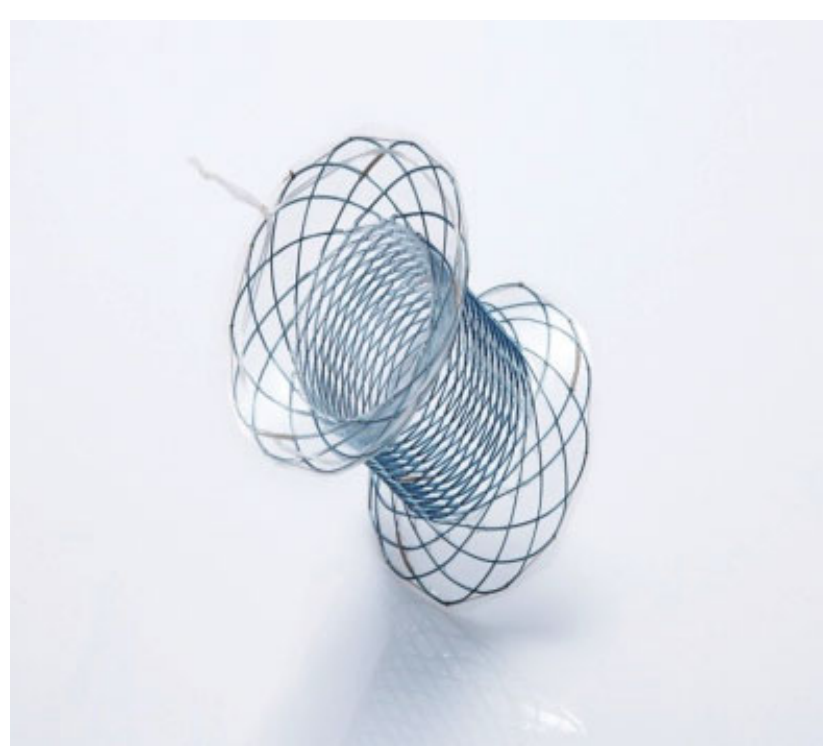

Fig. 5 Nagi stent.

\section{Biflanged Metal Stents}

NAGI stent (Taewoong Medical Co., Ltd., Ilsan, Korea) (-Fig. 5) has radio-opaque markers located at both ends and in the middle that allows fluoroscopy-guided placement. It comes in 2 and $3 \mathrm{~cm}$ lengths and a $26 \mathrm{~mm}$ diameter flange. It differs from the LAMS described earlier in having less apposition force, and is thus not considered suitable for procedures requiring stringer apposition between the anastomosed walls (-Table 2 ).

\section{Hybrid Stents}

Hybrid stents have been designed specifically for patients with failed ERCP in particularly useful for drainage in malignant biliary obstruction (MBO). These hybrid stents were developed with a fully covered distal portion and prevent bile leak and are proximally uncovered to prevent side branch blockage. They have inbuilt anti-migratory flaps.

GIOBOR (Taewoong Medical Co., Ltd.) flexible design and soft material take the stomach curves. It is available in 6 , $8,10 \mathrm{~cm}$ in length and $8,10 \mathrm{~mm}$ diameters. It has $70 \%$ covered part and $30 \%$ uncovered in the intrahepatic portion. It has three markers at both ends and two at the end of the covered portion.

In Hanarostent BPD (MI Tech, Seoul, Korea), the uncovered portion is $30 \mathrm{~mm}$ in length, while the distal trans-gastric

Table 2 Comparative data of Hybrid stents

\begin{tabular}{|l|l|l|l|l|l|l|}
\hline Stent type & $\begin{array}{l}\text { Stent } \\
\text { diameter }(\mathbf{m m})\end{array}$ & $\begin{array}{l}\text { Stent covered } \\
\text { length }(\mathbf{m m})\end{array}$ & $\begin{array}{l}\text { Stent } \\
\text { length }(\mathbf{c m})\end{array}$ & $\begin{array}{l}\text { Catheter } \\
\text { diameter } \\
\text { (French) }\end{array}$ & $\begin{array}{l}\text { Studied } \\
\text { applications }\end{array}$ & Stent type \\
\hline GIOBOR & 8,10 & 40,50 & 8,10 & 8.5 & HGS & Giobor \\
\hline Hanaro & 10 & 30 & 8,10 & 8.5 & HGS & Hanaro \\
\hline $\begin{array}{l}\text { Deus delivery } \\
\text { premounted stent }\end{array}$ & 6 & $35-85$ & 5,10 & 7 & HGS, CDS & $\begin{array}{l}\text { Deus delivery } \\
\text { premounted stent }\end{array}$ \\
\hline
\end{tabular}

Abbreviations: CDS, cholecochoduodenostomy; HGS, hepaticogastrostomy. 


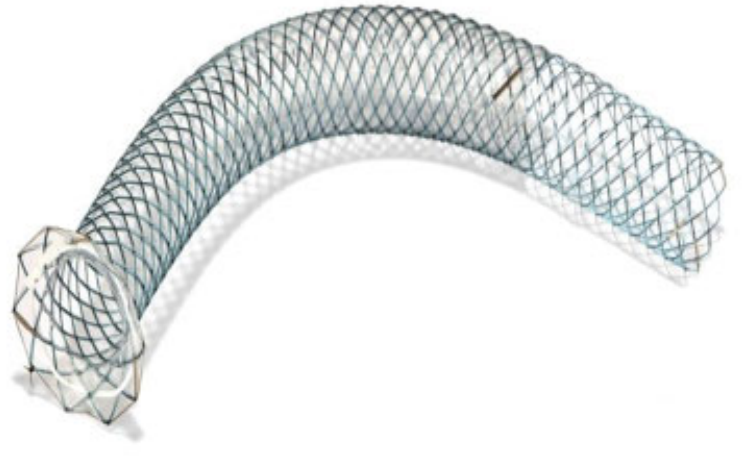

Fig. 6 GIOBOR stent.

silicone-covered portion depends on the length of the stent. The stent comes in $6,8,10 \mathrm{~cm}$ with a diameter of between 10 and $20 \mathrm{~mm}$ with an anti-migration rivet-type flared flap of $20 \mathrm{~mm}$ at the gastric extremity. The radio-opaque markers

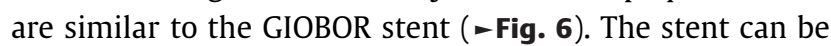
fully resheathed during delivery up to $70 \%$ deployment.

\section{Indications and Evidence}

Since the first report by Giovannini et al in $2001,{ }^{8}$ EUS-BD has become the procedure of choice replacing PTBD for failed ERCPs. This has been shown to reduce morbidity, stent blockage, re-intervention rates, and length of hospital stay as compared with PTBD. ${ }^{9-12}$ EUS-guided biliary drainage in such cases can be done by choledocho-duodenostomy, antegrade stenting, hepatico-gastrostomy, hepatic-duodenostomy. ${ }^{13}$ Emerging evidence suggests that EUS-BD is equivalent to ERCP for distal malignant obstruction. LAMS has been widely preferred over PS in malignant biliary blocks. There is level 1 evidence for use of EUS-BD as an alternative to ERCP in expert centers. ${ }^{14}$ Evidence from a recent systemic review suggests that EUS-BD has comparable technical and clinical success to ERCP. ${ }^{15}$ The type of stent used differs depending upon the level of obstruction. In general, short stents including LAMS are used for distal obstruction, while tubular stents are used for proximal obstruction.

EUS-guided drainage is the standard of care for symptomatic pancreatic pseudocysts and walled-off necrosis. While traditional surgery and percutaneous drainage have comparable outcomes albeit higher rates of fistula formation and sepsis, EUS-guided drainage has better morbidity, mortality, reduces the length of stay, and is minimally invasive. ${ }^{16}$ One randomized controlled trial (RCT) and one meta-analysis have shown equal efficacy of PS versus LAMS/BFMS, while another four metaanalyses have shown better efficacy with LAMS. ${ }^{17,18}$

EUS-guided transmural gall bladder drainage (GBD) is emerging as an alternative to percutaneous GBD for the management of acute cholecystitis in surgical high-risk patients. Moreover, "salvage" GBD with LAMS seems to be
Table 3 Choice of stents for PFC drainage

\begin{tabular}{|l|l|l|l|}
\hline \multirow{2}{*}{ Procedure } & \multicolumn{3}{l|}{ Type of stent } \\
\cline { 2 - 4 } & Plastic & BFMS & LAMS \\
\hline Pseudocyst & & X & X \\
\hline WON & $\checkmark$ & $\checkmark$ & \\
\hline
\end{tabular}

Abbreviations: BFMS, biflanged fully covered metal stent; LAMS, lumen apposing stents; PFC, pancreatic fluid collection; WON, walled off necrosis.

an attractive option in malignant obstructing conditions. This has the advantage of lumen apposition with low chances of bile leak, pneumothorax, and hematoma formation compared with percutaneous drainage even in the presence of ascites. Technical difficulties can appear due to the gall bladder being mobile hence only an LAMS stent would be suitable for deployment. ${ }^{19,20}$

EUS guided gastrojejunostomy with LAMS has been advocated recently for gastric outlet obstruction with comparable if not better outcomes. Duodenal stents come with the inherent problem of stent migration, tumor ingrowth and overgrowth. Clinical outcomes with enteral stenting are often poor while EUS-GJ has shown better clinical outcomes (GOOSS [gastric outlet obstruction scoring system] score), longer stent patency in recent clinical studies. ${ }^{21,22}$

EUS has also been advocated in pancreatic ductal pathology as an alternative to surgery but these procedures are technically demanding due to their small diameter, shorter length, and stiffer pancreatic parenchyma. Evidence is limited and interventions are done at select tertiary centers. ${ }^{23}$

\section{Choosing the Right Stent}

No comparative studies of available stents have been published. In the absence of published evidence, current recommendations are based upon evidence of efficacy for a particular indication, stent design, stent properties, and cost considerations ${ }^{24}$ (- Tables 3-5).

\section{Pancreatic Fluid Collections}

Current evidence suggests that plastic stents (PS) provide adequate drainage for both pseudocysts and walled off necrosis (WON). Comparative studies of plastic versus metal stents for WON have conflicting conclusions, but the weight of evidence tends to favor metal stents for WON. Lumen apposition is not so necessary for WON, as the wall of WON is a pseudo-wall, and is unlikely to retract away. Hence, both BFMS and LAMS have shown good efficacy for WON. A PS placed through a LAMS or BFMS prevents early blockage by necrotic debris, and probably prevents the stent from touching the opposite WON wall, thereby probably reducing post-procedure bleeding.

\section{EUS-Guided Biliary Drainage}

The choice of the stent is influenced by the level of obstruction and the type of procedure being performed.

Trans-papillary procedures (rendezvous and antegrade procedures) can be done when papilla is approachable. Because these procedures are trans-papillary, stents routinely used for ERCP (PS, uncovered metal stents, covered metal 
Table 4 Choice of stents for EUS-BD

\begin{tabular}{|c|c|c|c|c|c|}
\hline \multirow[t]{2}{*}{ Procedure } & \multicolumn{5}{|c|}{ Type of stent } \\
\hline & Plastic & Uncovered metal & Covered metal & LAMS & Tubular \\
\hline Rendezvous & $\checkmark$ & $\checkmark$ & $\checkmark$ & X & X \\
\hline Transluminal CDS $($ CBD $<15 \mathrm{~mm})$ & $?$ & $\times$ & $\checkmark$ & $?$ & X \\
\hline Transluminal CDS (CBD > $15 \mathrm{~mm})$ & $?$ & X & 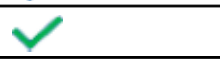 & $Y$ & X \\
\hline Transluminal HGS & $\checkmark$ & X & $?$ & X & \\
\hline Antegrade & X & $Y$ & X & X & X \\
\hline
\end{tabular}

Abbreviations: LAMS, lumen apposing stents; CDS, cholecochoduodenostomy; CBD, common bile duct; HGS, hepaticogastrostomy.

Table 5 Choice of stents for EUS- GB, G]

\begin{tabular}{|l|l|l|l|}
\hline \multirow{2}{*}{ Procedure } & \multicolumn{3}{l|}{ Type of stent } \\
\cline { 2 - 4 } & Plastic & BFMS & LAMS \\
\hline EUS GJ & X & X & \\
\hline GB drainage & X & X & \\
\hline
\end{tabular}

Abbreviations: BFMS, biflanged fully covered metal stent; EUS GJ, endoscopic ultrasonography-guided gastrojejunostomy; LAMS, lumen apposing stents.

stents) can be utilized for these procedures. These stents are cheaper compared with EUS-specific stents.

Trans-luminal procedures (Choledocho-duodenostomy, hepatico-gastrostomy) generally need EUS-specific stents although fully covered metal stents used for ERCP have also been utilized. A short fully covered metal stent or a LAMS is suitable. LAMS with a smaller diameter ( 6 or $8 \mathrm{~mm}$ ) may be utilized for choledocho-duodenostomy, especially if the common bile duct (CBD) is dilated to $12 \mathrm{~mm}$ or more. A long PS developed by Itoi et al is suitable for hepaticogastrostomy (HGS), especially in patients with benign strictures who need repeated procedures. This stent is unfortunately not available in most countries.

\section{Gallbladder Drainage and Gastro-enterostomy}

Both gallbladder drainage and gastro-enterostomy need a stent with strong lumen apposing force. A weak apposing force could result in separation of the walls (duodenum and GB, or stomach and jejunum), thus resulting in leak or perforation. Thus, LAMS (Axios or Spaxus) is the only suitable stents currently.

\section{Future Research}

While significant progress has taken place in the development of EUS-specific stents in the past decade, further research is needed for further improvements. These stents have large diameters, allowing free movement of solids and liquids from either side. This creates a problem of food material entering the WON cavity or the CBD. A valve-like mechanism is needed for the one-sided passage of fluid or necrotic material. Stents for WON need removal after 3 to 4 weeks. A bio-absorbable stent could be developed that does not need removal. The length of HGS stents and the length of the covered portion need standardization. Access stents need to be refined for patients needing repeated procedures.
Conflict of Interest

None declared.

\section{References}

1 Dhir V, Isayama H, Itoi T, et al. Endoscopic ultrasonographyguided biliary and pancreatic duct interventions. Dig Endosc 2017;29(04):472-485

2 Teoh AYB, Dhir V, Kida M, et al. Consensus guidelines on the optimal management in interventional EUS procedures: results from the Asian EUS group RAND/UCLA expert panel. Gut 2018;67 (07):1209-1228

3 Kedia P, Tyberg A, Kumta NA, et al. EUS-directed transgastric ERCP for Roux-en-Y gastric bypass anatomy: a minimally invasive approach. Gastrointest Endosc 2015;82(03):560-565

4 Weilert F, Binmoeller KF. Specially designed stents for translumenal drainage. Gastrointest Interv 2015;4:40-45

5 Mangiavillano B, Pagano N, Baron TH, et al. Biliary and pancreatic stenting: Devices and insertion techniques in therapeutic endoscopic retrograde cholangiopancreatography and endoscopic ultrasonography. World J Gastrointest Endosc 2016;8(03):143-156

6 Umeda J, Itoi T, Tsuchiya T, et al. A newly designed plastic stent for EUS-guided hepaticogastrostomy: a prospective preliminary feasibility study (with videos). Gastrointest Endosc 2015;82(02): 390-396.e2

7 Binmoeller KF, Shah J. A novel lumen-apposing stent for transluminal drainage of nonadherent extraintestinal fluid collections. Endoscopy 2011;43(04):337-342

8 Giovannini M, Moutardier V, Pesenti C, Bories E, Lelong B, Delpero JR. Endoscopic ultrasound-guided bilioduodenal anastomosis: a new technique for biliary drainage. Endoscopy 2001;33(10): 898-900

9 Sharaiha RZ, Khan MA, Kamal F, et al. Efficacy and safety of EUSguided biliary drainage in comparison with percutaneous biliary drainage when ERCP fails: a systematic review and meta-analysis. Gastrointest Endosc 2017;85(05):904-914

10 Bang JY, Navaneethan U, Hasan M, Hawes R, Varadarajulu S. Stent placement by EUS or ERCP for primary biliary decompression in pancreatic cancer: a randomized trial (with videos). Gastrointest Endosc 2018;88(01):9-17

11 Dhindsa BS, Mashiana HS, Dhaliwal A, et al. EUS-guided biliary drainage: a systematic review and meta-analysis. Endosc Ultrasound 2020;9(02):101-109

12 Tsuchiya T, Teoh AYB, Itoi T, et al. Long-term outcomes of EUSguided choledochoduodenostomy using a lumen-apposing metal stent for malignant distal biliary obstruction: a prospective multicenter study. Gastrointest Endosc 2018;87(04): 1138-1146

13 Cho DH, Lee SS, Oh D, et al. Long-term outcomes of a newly developed hybrid metal stent for EUS-guided biliary drainage (with videos). Gastrointest Endosc 2017;85(05):1067-1075

14 Lee TH, Choi JH, Park H, et al. Similar efficacies of endoscopic ultrasound-guided transmural and percutaneous drainage for 
malignant distal biliary obstruction. Clin Gastroenterol Hepatol 2016;14(07):1011-1019.e3

15 Paik WH, Lee TH, Park DH, et al. EUS-guided biliary drainage versus ERCP for the primary palliation of malignant biliary obstruction: a multicenter randomized clinical trial. Am J Gastroenterol 2018;113(07):987-997

16 Hammad T, Khan MA, Alastal Y, et al. Efficacy and safety of lumenapposing metal stents in management of pancreatic fluid collections: are they better than plastic stents? A systematic review and meta-analysis. Dig Dis Sci 2018;63(02):289-301

17 Shah R, Basha J, Rana S, et al. Endoscopic management of pancreatic fluid collections: guidelines of Society of Gastrointestinal Endoscopy of India and Indian EUS Club. Dig Endosc 2021; 12:3-10

18 Yang J, Chen YI, Friedland S, et al. Lumen-apposing stents versus plastic stents in the management of pancreatic pseudocysts: a large, comparative international, multicenter study. Endoscopy 2019;51(11):1035-1043

19 Walter D, Teoh AY, Itoi T, et al. EUS-guided gall bladder drainage with a lumen-apposing metal stent: a prospective long-term evaluation. Gut 2016;65(01):6-8[PubMed] [Google Scholar]
20 Teoh AYB, Serna C, Penas I, et al. Endoscopic ultrasound-guided gallbladder drainage reduces adverse events compared with percutaneous cholecystostomy in patients who are unfit for cholecystectomy. Endoscopy 2017;49(02):130-138

21 Itoi T, Ishii K, Ikeuchi N, et al. Prospective evaluation of endoscopic ultrasonography-guided double-balloon-occluded gastrojejunostomy bypass (EPASS) for malignant gastric outlet obstruction. Gut 2016;65(02):193-195

22 Bukhari M, Kowalski T, Nieto J, et al. An international, multicenter, comparative trial of EUS-guided gastrogastrostomy-assisted ERCP versus enteroscopy-assisted ERCP in patients with Rouxen-Y gastric bypass anatomy. Gastrointest Endosc 2018;88(03): 486-494

23 Giovannini M. Endoscopic ultrasound-guided pancreatic duct drainage: Ready for the prime time? Endosc Ultrasound 2017;6 (05):281-284

24 Teoh AY, Ng EK, Chan SM, et al. Ex vivo comparison of the lumenapposing properties of EUS-specific stents (with video). Gastrointest Endosc 2016;84(01):62-68 